\section{Case Reports in Oncology}

Case Rep Oncol 2019;12:554-559

DOI: $10.1159 / 00050176$

Published online: July 16,2019

(C) 2019 The Author(s)

Published by S. Karger AG, Base

www.karger.com/cro

This article is licensed under the Creative Commons Attribution-NonCommercial 4.0 International License (CC BY-NC) (http://www.karger.com/Services/OpenAccessLicense).

Usage and distribution for commercial purposes requires written permission.

\title{
Pure Mucinous Breast Carcinoma with Micropapillary Pattern (MUMPC): A Case Report
}

\author{
Yuka Asano $^{a}$ Shinichiro Kashiwagi ${ }^{a} \quad$ Mizuki Nagamori ${ }^{a}$ Sayaka Tanaka $^{b}$ \\ Yuko Kuwae $^{b}$ Ryosuke Amano ${ }^{c}$ Tsutomu Takashima ${ }^{a}$ \\ Masahiko Ohsawa ${ }^{\mathrm{b}}$ Kosei Hirakawa ${ }^{\mathrm{a}}$ Masaichi Ohira ${ }^{\mathrm{a}}$ \\ aDepartment of Breast and Endocrine Surgery, Osaka City University Graduate School of \\ Medicine, Osaka, Japan; bDepartment of Diagnostic Pathology, Osaka City University \\ Graduate School of Medicine, Osaka, Japan; 'Department of Hepato-Biliary-Pancreatic \\ Surgery, Osaka City University Graduate School of Medicine, Osaka, Japan
}

\section{Keywords}

Pure mucinous carcinoma with micropapillary pattern · Pure mucinous carcinoma - Invasive micropapillary carcinoma · Mammary tumor · Surgery

\begin{abstract}
Pure mucinous breast carcinoma with micropapillary pattern (MUMPC) was proposed as a new histopathological variant of pure mucinous carcinoma (PMC) with tumor cells forming a micropapillary architecture. The Classification of Tumours of the Breast by the World Health Organization, however, does not differentiate MUMPC as a distinct subtype. There is currently no consensus whether tumors that exhibit these features are classified as PMC or invasive micropapillary carcinoma (IMPC) with associated mucin production. A 45-year-old woman was examined for a tumor in her left breast. Upon physical examination, an elastic hard mass of around $5 \mathrm{~cm}$ along with accompanying skin flare and ulceration was palpated in the upper outer quadrant of the left breast. Mammary ultrasonography revealed a clearly marginated hypoechoic tumor of $55.0 \times 46.9 \times 37.0 \mathrm{~mm}$ in size in the upper outer quadrant of the left breast. A vacuum-assisted biopsy (VAB) was performed in the same site and histopathological diagnosis of PMC was made. Contrast-enhanced magnetic resonance imaging (MRI) showed a T1W1 low-intensity signal and a T2W1 high-intensity signal at the primary focus, ring enhancement of the tumor margin, and stranding enhancement inside the tumor. A preoperative
\end{abstract}


diagnosis of left breast cancer (PMC), CT4bN1M0, stage IIIB, luminal B-like was made. We performed a simple mastectomy with axillary lymph node dissection. A $55.0 \times 48.1 \times 37.1 \mathrm{~mm}$ tumor with the gelatinous cut surface was excised. Histopathological examination of the excised specimen revealed mucin lake formation in the tumor containing clusters of atypical cells. The atypical cells showed swollen, irregular nuclei and a papillary growth pattern that lead to the diagnosis of MUMPC.

(C) 2019 The Author(s)

Published by S. Karger AG, Basel

\section{Introduction}

Pure mucinous breast carcinoma with micropapillary pattern (MUMPC) was proposed by $\mathrm{Ng}$ in 2002 as a new histopathological variant of pure mucinous carcinoma (PMC) with tumor cells forming a micropapillary architecture [1]. The Classification of Tumours of the Breast by the World Health Organization (2012), however, does not differentiate MUMPC as a distinct subtype [2]. There is currently no consensus whether tumors that exhibit these features are classified as PMC or invasive micropapillary carcinoma (IMPC) with associated mucin production. For this reason, although MUMPC shows pathological characteristics suggestive of PMC, reports suggest that biologically it should be considered as IMPC [3-6]. Here, we have reported a case of MUMPC along with a review of the literature.

\section{Case Presentation}

A 45-year-old woman was examined for a tumor in her left breast. The patient had no significant and relevant medical or family history. Upon physical examination, an elastic hard mass of around $5 \mathrm{~cm}$ along with accompanying skin flare and ulceration was palpated in the upper outer quadrant of the left breast (Fig. 1a). Multiple lymph nodes in the left axilla were also palpable. Mammary ultrasonography revealed a clearly marginated hypoechoic tumor of $55.0 \times 46.9 \times 37.0 \mathrm{~mm}$ in size in the upper outer quadrant of the left breast (Fig. 1b). A vacuumassisted biopsy (VAB) was performed in the same site and histopathological diagnosis of PMC was made (Fig. 1c). The immunohistochemical staining revealed a strongly positive diffused expression of estrogen receptor (ER) and progesterone receptor (PgR), negative expression of human epidermal growth factor receptor 2 (HER2), and high expression of Ki-67. Computed tomography (CT) exhibited no distant metastases, although axillary lymph node metastases were suspected. Contrast-enhanced magnetic resonance imaging (MRI) showed a T1W1 lowintensity signal and a T2W1 high-intensity signal at the primary focus, ring enhancement of the tumor margin, and stranding enhancement inside the tumor (Fig. 2a, b). Bone scintigraphy also revealed no bone metastasis. A preoperative diagnosis of left breast cancer (PMC), cT4bN1M0, stage IIIB, luminal B-like was made.

We performed a simple mastectomy with axillary lymph node dissection. A $55.0 \times 48.1 \times$ $37.1 \mathrm{~mm}$ tumor with the gelatinous cut surface was excised (Fig. 3a). Histopathological examination of the excised specimen revealed mucin lake formation in the tumor containing clusters of atypical cells (Fig. 3b). The atypical cells showed swollen, irregular nuclei and a papillary growth pattern that lead to the diagnosis of MUMPC. The expression of ER and PgR were diffused and strongly positive, HER2 expression was negative, and Ki-67 expression was high. Based on these findings, the final diagnosis of left breast cancer (MUMPC), pT3N0M0, stage IIB, luminal B-like was made. Adjuvant chemotherapy was initiated after the surgery (adriamycin and cyclophosphamide [AC] followed by weekly paclitaxel) $[7,8]$ and an endocrine 
therapy was planned (tamoxifen $20 \mathrm{mg} /$ day) [9]. No metastatic recurrence has occurred until the time of drafting this case report, 3 months after the surgery.

\section{Discussion/Conclusion}

MUMPC is a rare histopathological variant of breast cancer that reportedly accounts for $<1 \%$ of all breast cancers [1] and $12-35 \%$ of all PMC cases [3, 10]. Nevertheless, there is no consensus whether MUMPC should be considered as a subtype of PMC or IMPC [2].

PMC is reported to account for approximate $2-3 \%$ of all breast cancers, $\geq 90 \%$ of all cancers that exhibit infiltration associated with mucous secretion $[2,11]$, and histopathologically it has a favorable prognosis $[12,13]$. On the other hand, IMPC is a distinct subtype of invasive ductal breast cancer having histopathological characteristics of a micropapillary structure and was first reported by Siriaunkgul and Tavassoli in 1993 [14]. Void spaces are observed between the cancer nest and the surrounding stroma, and the tumor cell clumps appear to be suspended in the transparent and structureless space. Tumor cells show reverse polarity, also called an inside-out growth pattern, whereby the ductal surface (stromal surface) faces outwards and not inwards towards the cancer nest [15]. IMPC is characterized by prominent lymphovascular invasion and lymph node metastases and is often reported to have a poor prognosis [16-18]. In other words, the PMC subtype has a favorable prognosis whereas the IMPC subtype has a poor prognosis as compared to the normal invasive breast cancer.

Although MUMPC resembles PMC from a histopathological viewpoint in showing clumps of atypical cells suspended in mucous lakes, the papillary growth pattern exhibited by these atypical cells differentiates MUMPC from PMC. MUMPC also follows an IMPC-like clinical course with micropapillary cancer cells leading to lymphovascular invasion and lymph node metastases [6]. In the NCCN guidelines, PMC is regarded as "a histological type with a favorable prognosis" in a uniform manner, and "treatment for a histological type with a favorable prognosis" is recommended [19]. However, the treatment of MUMPC resembles that of IMPC. Consequently, careful attention is required to differentiate between PMC and MUMPC as they differ in their malignant potentials.

\section{Acknowledgements}

We thank Yayoi Matsukiyo and Tomomi Okawa (Department of Breast and Endocrine Surgery, Osaka City University Graduate School of Medicine) for helpful advice regarding data management.

\section{Statement of Ethics}

Written ethical approval for the publication on the present case report was obtained from the patient.

\section{Disclosure Statement}

The authors declare that they have no conflicts of interest to disclose. 
Asano et al.: Pure Mucinous Breast Carcinoma with Micropapillary Pattern (MUMPC): A Case Report

\section{Funding Sources}

No funding was received for this article and the authors have no conflicts of interest directly relevant to this report.

\section{Author Contributions}

All authors were involved in the preparation of this manuscript. YA collected the data, and wrote the manuscript. YA, SK, MN, RA and TT performed the operation and designed the study. ST, YK, and MOhs perfomed pathological diagnosis. SK and KH summarized the data and revised the manuscript. $\mathrm{KH}$ and MOhi made substantial contribution to the study design, performed the operation, and revised the manuscript. All authors read and approved the final manuscript.

\section{References}

1 Ng WK. Fine-needle aspiration cytology findings of an uncommon micropapillary variant of pure mucinous carcinoma of the breast: review of patients over an 8-year period. Cancer. 2002 Oct;96(5):280-8.

2 Lakhani SR, Ellis IO, Schnitt SJ. WHO classification of tumours of the breast. World Health Organization classification of tumours. 4th ed. Lyon: IARC press; 2012.

3 Barbashina V, Corben AD, Akram M, Vallejo C, Tan LK. Mucinous micropapillary carcinoma of the breast: an aggressive counterpart to conventional pure mucinous tumors. Hum Pathol. 2013 Aug;44(8):1577-85.

4 Ranade A, Batra R, Sandhu G, Chitale RA, Balderacchi J. Clinicopathological evaluation of 100 cases of mucinous carcinoma of breast with emphasis on axillary staging and special reference to a micropapillary pattern. J Clin Pathol. 2010 Dec;63(12):1043-7.

5 Zhang H, Qiu L, Peng Y. The sonographic findings of micropapillary pattern in pure mucinous carcinoma of the breast. World J Surg Oncol. 2018 Jul;16(1):151.

6 Liu F, Yang M, Li Z, Guo X, Lin Y, Lang R, et al. Invasive micropapillary mucinous carcinoma of the breast is associated with poor prognosis. Breast Cancer Res Treat. 2015 Jun;151(2):443-51.

7 Henderson IC, Berry DA, Demetri GD, Cirrincione CT, Goldstein LJ, Martino S, et al. Improved outcomes from adding sequential Paclitaxel but not from escalating Doxorubicin dose in an adjuvant chemotherapy regimen for patients with node-positive primary breast cancer. J Clin Oncol. 2003 Mar;21(6):976-83.

8 Mamounas EP, Bryant J, Lembersky B, Fehrenbacher L, Sedlacek SM, Fisher B, et al. Paclitaxel after doxorubicin plus cyclophosphamide as adjuvant chemotherapy for node-positive breast cancer: results from NSABP B-28. J Clin Oncol. 2005 Jun;23(16):3686-96.

9 Early Breast Cancer Trialists' Collaborative Group (EBCTCG). Effects of chemotherapy and hormonal therapy for early breast cancer on recurrence and 15-year survival: an overview of the randomised trials. Lancet. 2005 May;365(9472):1687-717.

10 Bal A, Joshi K, Sharma SC, Das A, Verma A, Wig JD. Prognostic significance of micropapillary pattern in pure mucinous carcinoma of the breast. Int J Surg Pathol. 2008 Jul;16(3):251-6.

11 Komaki K, Sakamoto G, Sugano H, Morimoto T, Monden Y. Mucinous carcinoma of the breast in Japan. A prognostic analysis based on morphologic features. Cancer. 1988 Mar;61(5):989-96.

12 Di Saverio S, Gutierrez J, Avisar E. A retrospective review with long term follow up of 11,400 cases of pure mucinous breast carcinoma. Breast Cancer Res Treat. 2008 Oct;111(3):541-7.

13 Kashiwagi S, Onoda N, Asano Y, Noda S, Kawajiri H, Takashima T, et al. Clinical significance of the subclassification of 71 cases mucinous breast carcinoma. Springerplus. 2013 Sep;2(1):481.

14 Siriaunkgul S, Tavassoli FA. Invasive micropapillary carcinoma of the breast. Mod Pathol. 1993 Nov;6(6):660-2.

15 Guo X, Chen L, Lang R, Fan Y, Zhang X, Fu L. Invasive micropapillary carcinoma of the breast: association of pathologic features with lymph node metastasis. Am J Clin Pathol. 2006 Nov;126(5):740-6.

16 Kim MJ, Gong G, Joo HJ, Ahn SH, Ro JY. Immunohistochemical and clinicopathologic characteristics of invasive ductal carcinoma of breast with micropapillary carcinoma component. Arch Pathol Lab Med. 2005 Oct;129(10):1277-82.

17 Chen L, Fan Y, Lang RG, Guo XJ, Sun YL, Cui LF, et al. Breast carcinoma with micropapillary features: clinicopathologic study and long-term follow-up of 100 cases. Int J Surg Pathol. 2008 Apr;16(2):155-63. 
 Oncology}

18 Yu JI, Choi DH, Park W, Huh SJ, Cho EY, Lim YH, et al. Differences in prognostic factors and patterns of failure between invasive micropapillary carcinoma and invasive ductal carcinoma of the breast: matched casecontrol study. Breast. 2010 Jun;19(3):231-7.

19 National Comprehensive Cancer Network. NCCN Clinical Practice Guideline in Oncology (NCCN Guidelines ${ }^{\circledR}$ ) Breast Cancer. Version 3.2018, BINV-4. Available from: https://www2.trikobe.org/nccn/guideline/breast/english/breast.pdf.
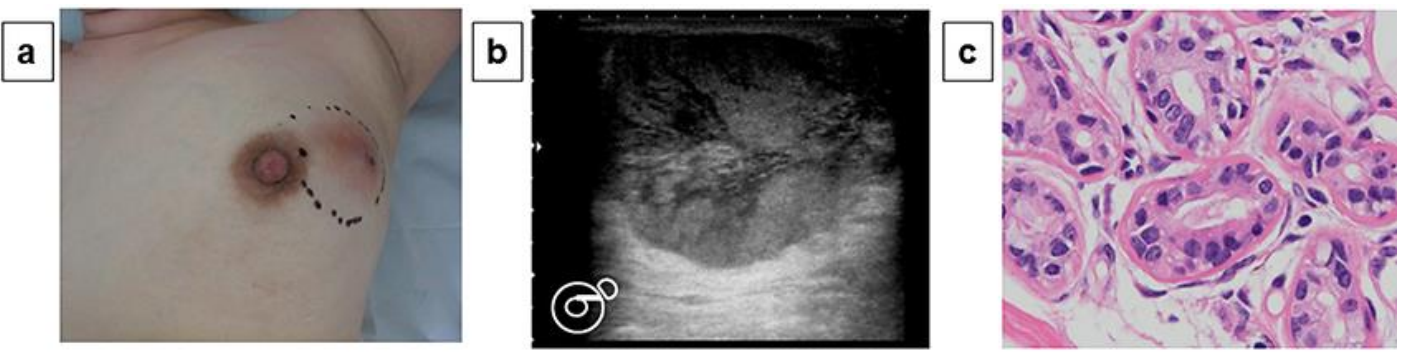

Fig. 1. Preoperative findings: Upon physical examination, an elastic hard mass of around $5 \mathrm{~cm}$ along with accompanying skin flare and ulceration was palpated in the upper outer quadrant of the left breast (a). Mammary ultrasonography revealed a clearly marginated hypoechoic tumor of $55.0 \times 46.9 \times 37.0 \mathrm{~mm}$ in size in the upper outer quadrant of the left breast (b). A vacuum-assisted biopsy was performed in the same site and histopathological diagnosis of PMC was made (c: $\times 400$, hematoxylin and eosin stain).

\section{a}

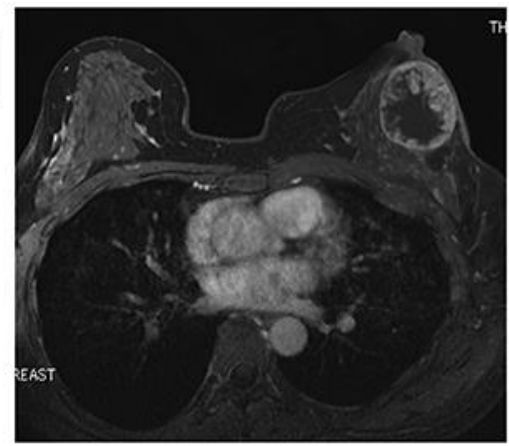

\section{b}

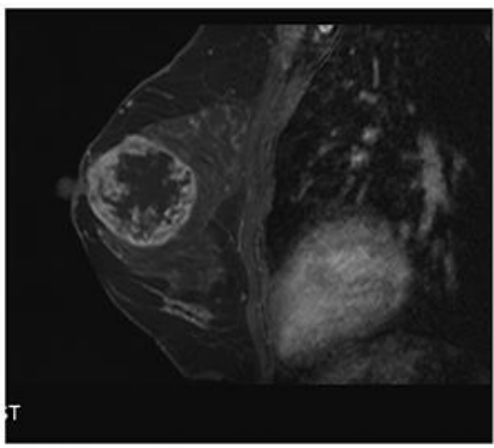

Fig. 2. Magnetic resonance imaging findings: Contrast-enhanced magnetic resonance imaging showed a T1W1 low-intensity signal and a T2W1 high-intensity signal at the primary focus, ring enhancement of the tumor margin, and stranding enhancement inside the tumor (a: transverse plane) (b: sagittal plane). 

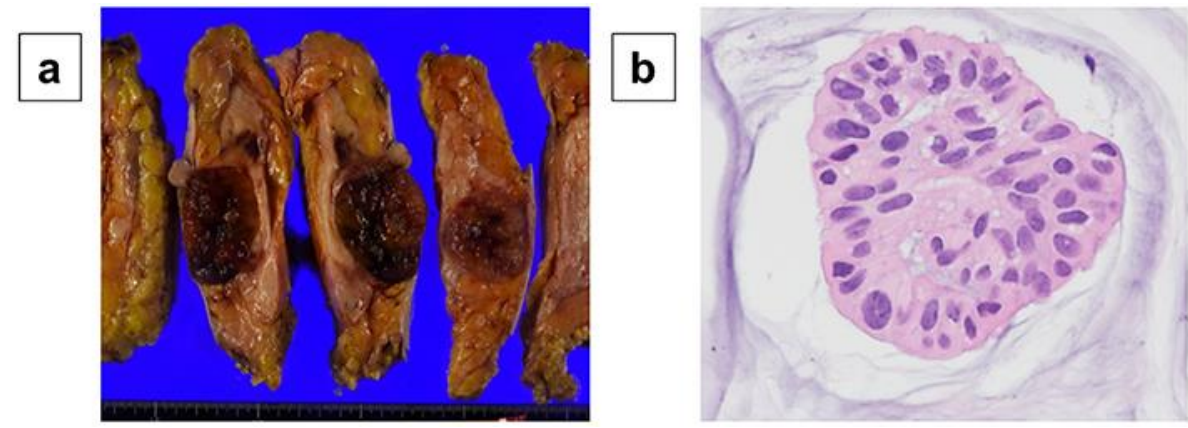

Fig. 3. Postoperative findings: A $55.0 \times 48.1 \times 37.1 \mathrm{~mm}$ tumor with the gelatinous cut surface was excised (a). Histopathological examination of the excised specimen revealed mucin lake formation in the tumor containing clusters of atypical cells ( $b$ : $\times 400$, hematoxylin and eosin stain).

Asano et al.: Pure Mucinous Breast Carcinoma with Micropapillary Pattern (MUMPC): A Case Report 